\title{
O que dizem os professores indígenas Tembé sobre a educação escolar e o futuro da aldeia: um estudo sobre as suas representações
}

\author{
Glauber Ranieri Martins da Silva \\ Ivany Pinto Nascimento \\ Universidade Federal do Pará (Brasil))
}

\section{Resumo}

presente estudo compõe parte da pesquisa realizada com professores indígenas Tembé, na Terra Indígena do Alto Rio Guamá. Neste artigo, analisamos o que dizem os professores Tembé sobre a educação escolar de seu povo e as implicações para o futuro da aldeia. Para tanto, utilizamos a teoria das representações sociais (TRS) na perspectiva de Moscovici. O instrumento de coleta de dados foi a entrevista narrativa e a seleção dos sujeitos e obedeceu a critérios previamente definidos. $\bigcirc$ tratamento e a análise dos dados seguiram as referências da TRS, assim, recorremos ao agrupamento dos dados pelas unidades de sentidos e a elaboração de temáticas correspondentes. Dentre os resultados, destacamos que as representações sociais de professores Tembé sobre a educação escolar de seu povo são objetivadas e ancoradas em grande medida em um currículo escolar voltado para não-indígenas. Desta forma, o futuro se encontra ameaçado, sobretudo, quanto à língua materna e aos ritos tradicionais indígenas.

Palavras-chave: Educação escolar indígena. Identidade. Representações sociais. Futuro.

\section{What the Tembé indigenous teachers say about school education and the future of the village: a study of their representations}

\begin{abstract}
The present study is part of the research carried out with Tember indigenous teachers in the upper Rio Guamá indigenous land. In this article we analyze what the Tembé professors say about the school education of their people and the implications in the future of the village. To do so, we applied the social representations theory (SRT) from Moscovici. The data collection instrument was the narrative interview and the selection of the subjects followed the previously defined criteria. The treatment and analysis of the data followed the references of the TRS, thus, we seek to the grouping of the data by the units of senses and the elaboration of corresponding themes. Among the results we highlight that the social representations of Tembe teachers about the school education of their people are objected and anchored to a large extent in a in a non-indigenous school curriculum. In this way, the future is threatened, mainly, by the mother tongue and traditional indigenous rites.
\end{abstract}

Keywords: Indigenous school education. Identity. Social representations. Future. 
que dizem os professores indígenas Tembé sobre a educação escolar e o futuro da aldeia: um estudo sobre as suas representações

\section{Lo que dicen los maestros indígenas Tembé sobre la educación esco- lar y el futuro de la aldea: un estudio de sus representaciones}

\section{Resumen}

El presente estudio es parte de la investigación realizada con maestros indígenas Tembé en la tierra indígena del Alto Guamá. En este artículo, analizamos lo que dicen los profesores de Tembé sobre la educación escolar de su gente y las implicaciones en el futuro de la aldea. Para ello, utilizamos la teoría de las representaciones sociales (TRS) de Moscovici. El instrumento de recolección de datos fue la entrevista narrativa y la selección de sujetos y obedeció criterios previamente definidos. El tratamiento y análisis de los datos siguieron las referencias del TRS, por lo tanto, recurrimos a la agrupación de los datos por las unidades de los sentidos y la elaboración de los temas correspondientes. Entre los resultados, destacamos que las representaciones sociales de los maestros de Tembé sobre la educación escolar de su pueblo están objetivadas y ancladas en gran medida en un currículo escolar no indígena. De esta manera, el futuro se ve amenazado, especialmente, en lo que respecta a la lengua materna y los ritos indígenas tradicionales.

Palabras clave: Educación escolar indígena. Identidad. Representaciones sociales. Futuro.

\section{Introdução}

presente artigo objetiva a apresentação de resultados da pesquisa realizada com professores indígenas Tembé na Terra Indígena do Alto Rio Guamá (TIARG). $\bigcirc$ estudo consiste em analisar as representações sociais desses professores sobre o futuro da aldeia e a educação. A TIARG possui 279 mil hectares, se estende por vários municípios paraenses, como Santa Luzia do Pará e Paragominas, e fica às margens direita do Rio Guamá e esquerda do Rio Gurupi, na divisa dos estados do Pará e Maranhão. É composta por de 33 aldeias, sendo 17 na região do Gurupi, sul do território, e 16 na região do Guamá, ao norte. Segundo o Plano de Gestão Territorial e Ambiental PGTA/ TIARG (2018), vivem na terra indígena aproximadamente 4.168 pessoas, das quais 2.546 são indígenas. Os lóci de nossa pesquisa foram as aldeias São Pedro e ltuwaçu, ambas na parte norte do território.

A concepção de indígena é, segundo o Estatuto do Índio (Lei 6.001 / 1973), "[...] todo indivíduo de origem e ascendência pré-colombiana que se identifica e é identificado como pertencente a um grupo étnico cujas características culturais o distinguem da sociedade nacional" (BRASIL, 1973). 
Assim, a Fundação Nacional do Índio (FUNAI) considera o reconhecimento de um indígena por esses dois critérios: a) autodeclaração e consciência de sua identidade indígena e, b) o reconhecimento por parte do grupo indígena de origem.

No Brasil, há 896,9 mil indígenas, 305 etnias com 274 línguas, distribuídos por todo o território nacional (IBGE, 2010). Muitas etnias tiveram suas culturas violentadas desde a colonização (século XVI) e, nos dias atuais, sofrem sucessivas investidas contra seus modos de vida e seus territórios.

É necessário aprofundar os debates sobre os povos indígenas nas perspectivas educacional, social, econômica e política, uma vez que as concepções de extrema direita se posicionam pela revisão/negação de direitos indígenas, como a demarcação de terras, o reconhecimento étnico-territorial, a educação e a saúde diferenciadas, dentre outros.

Essas concepções afirmam, de maneira geral, que há muita terra para pouco índio e que tais terras deveriam estar disponíveis para a exploração agrícola ou pecuária, ou ainda para o desenvolvimento de potenciais para as áreas de mineração. Isto representa ameaça à vida deste povo, suas perspectivas etnoterritoriais e etnoeducacionais.

Isto ratifica que a atual conjuntura político-ideológica valoriza a economia e o lucro em detrimento da vida do indígena. Vale destacar que a negação da identidade indígena pelos governantes se baseia na justificativa de que o indígena transforma a sua identidade ao adquirir técnicas, a priori, urbano-industriais, como a utilização de mídias e sistemas eletroeletrônicos e informacionais.

Embora a propagação dessas inovações na aldeia Tembé ocorra em menor escala, quando comparados aos espaços urbanos, as mudanças no território Tembé são significativamente maiores, se comparadas às ocorridas nas cidades. $\bigcirc$ contato com culturas diversas reflete "[...] a própria situação cultural e linguística de cada grupo, havendo principalmente na região do Guamá um significativo declínio da língua Tembé de modo que o português tornou-se a sua primeira língua" (MARRA, 2015, p. 218).

Em geral, a visão do branco' sobre o indígena está ligada a estereótipos produzidos pela colonização. Não há a compreensão do significado de ser indígena, de sua história e da sua cultura. Com efeito, a população 
que dizem os professores indígenas Tembé sobre a educação escolar e o futuro da aldeia: um estudo sobre as suas representações

não-indígena acredita na existência de uma estagnação sociocultural, educacional, econômica e política do indígena, como observamos nos escritos de Guarany:

Como há muito tratado pela história, poderia dizer que era assim que começavam e terminavam os textos: os índios foram importantes na formação da sociedade brasileira; os índios caçavam, habitavam ocas, comiam raízes e Tupã era seu deus; os índios eram brutos, seres bestiais ou, para outros, o bom selvagem. Enfim, inúmeros eram os escritos em que se retratava o índio do início da colonização, mas sempre estereotipados (GUARANY, 2006, p. 146).

Não podemos negar, entretanto, que, diante das transformações e avanços que dinamizam a sociedade brasileira, os vetores da modernização impõem mudanças nos modos de pensar, sentir e agir deste povo. As práticas de vivência cotidiana, o tempo, a alimentação, o uso de medicamentos e outros saberes se entrelaçam de tal maneira, que as tradições culturais - sustentáculos da identidade indígena - são ameaçadas.

A sobrevivência da identidade cultural (HALL, 2006) está diretamente ligada à capacidade de compreensão da modernização sem que haja a destruição dos elementos que compõem essa identidade, muito embora inúmeras conquistas garantam direitos indígenas sobre saúde, educação e preservação das identidades e dos territórios sejam reconhecidos na Constituição Federal de 1988, na Lei 6.001/73, que dispõe sobre o Estatuto do Índio, e na Declaração das Nações Unidas, sobre os direitos dos povos indígenas de 2007, entre outras.

Neste sentido, a escola possui papel fundamental tanto para a manutenção da cultura da aldeia, a valorização dos saberes locais e a preservação da identidade quanto para a compreensão critica dos modos de vida exógenos que exercem pressões para homogeneização cultural.

As pesquisas sobre educação dos povos indígenas figuram sob diversas acepções tanto em nível governamental quanto acadêmico. Segundo Cohn, "[...] aos índios eram oferecidos serviços educacionais para mudar o que são e para serem integrados à sociedade que os envolve" $(\mathrm{COHN}, 2005$, p. 486). 
O relatório publicado por Maroldi (2018) sobre a produção científica relacionada às populações indígenas indica que, no Brasil, tal produção aumentou nas últimas décadas. As pesquisas sobre temáticas relacionadas à educação indígena, especialmente nas décadas de 1990 e 2000, trazem preocupações voltadas para estudos de caso etnográficos sobre as experiências dos povos indígenas com a escola, concentradas em aspectos antropológicos e linguísticos, com a tendência para valorizar os indígenas ora como heróis resistentes, ora como vítimas e passivos.

Contudo, verificamos que essas produções acadêmicas sobre educação indígena ainda são incipientes para dar sustentação à formação do professor indígena e orientar práticas pedagógicas concernentes com a cultura específica deste povo.

Vale destacar que, inicialmente, a educação escolar indígena não se propunha, a priori, considerar e reconhecer as singularidades dos sujeitos indígenas. Daí as reivindicações dos indígenas por escolas que garantissem uma educação diferenciada. Esta educação deveria estimular o desenvolvimento de habilidades e aprendizagens que objetivassem o protagonismo desses sujeitos e a necessidade de reflexão sobre si próprios.

Uma das reivindicações dos Tembé quanto à educação escolar reside na adequação da escola ao tempo da aldeia. Essa demanda surge em função da escola se constituir em um paradoxo entre os conhecimentos acadêmicos e o modo de vida indígena até os dias atuais. Desse modo, a educação escolar negligencia aspectos da cultura como a educação familiar, os modos de sobrevivência - caça, pesca, plantio -, e a cosmologia indígena, compreendida como "[...] modelos complexos que expressam suas concepções a respeito da origem do Universo e de todas as coisas que existem no mundo" (TEIXEIRAPINTO, 1997), dentre outros.

Dessa forma, a realidade das escolas indígenas é similar à enfrentada pelas escolas públicas não-indígenas: significa que existe inadequação entre o material didático e as especificidades desses povos. Inclui-se aí a carência de professores e profissionais de apoio bem como a falta de recursos tecnológicos e de ambiente pedagógico com infraestrutura que atenda às necessidades educacionais do alunado.

Na TIARG, há escolas de ensino fundamental e, em algumas aldeias, há ensino médio. Essas escolas são mantidas pelos municípios ou pelo estado 
O que dizem os professores indígenas Tembé sobre a educação escolar e o futuro da aldeia: um estudo sobre as suas representações

e os profissionais, professores e técnicos são, em sua grande maioria, contratados em caráter temporário, sejam indígenas ou não.

O currículo da escola Tembé compõe-se de uma mescla entre o currículo praticado pelos sistemas de ensino - língua portuguesa e artes, ciências naturais e matemática, ciências humanas e sociais - e alguns conteúdos, disciplinas ou programas introduzidos pela comunidade, como notório saber, contação de histórias e língua materna -, em conformidade com o Referencial Curricular Nacional para as Escolas Indígenas (RCNEI).

Com base no RCNEI, uma educação indígena diferenciada e de qualidade é aquela capaz de articular elementos acadêmicos e saberes tradicionais indígenas para a formação cidadã e da identidade.

Diante dessas e outras dificuldades, os Tembé e outras etnias reivindicam a formação específica e em nível superior para suprir as necessidades de suas comunidades, já que existe grande parcela de profissionais não-indígenas atuando nas escolas das aldeias.

Em atenção a isso, a partir de 2012, a Universidade do Estado do Pará iniciou o curso de Licenciatura Intercultural Indígena com o objetivo de formar professores indígenas para atuar na educação básica nas áreas de ciências humanas e sociais, ciências da natureza e matemáticas, linguagens e artes. $\bigcirc$ curso foi ofertado para os povos Gavião, Surui Aikewara e Tembé-Guamá, que o concluíram em 2016. Em 2013, ofertou turmas para os Wai Wai e os povos da região Tapajós Arapyú-Santarém (Borari, Munduruku, Arapyú, entre outros). Em 2015, aos Kayapó e em 2016, aos Asurini do Trocará, Tapajós ArapyúCaruci e Tembé-Gurupi.

Nessa lógica, a percepção dos próprios Tembé sobre a educação, suas possibilidades e desafios, no que tange à preservação da sua cultura e identidade para o futuro, compõe importante objeto de investigação para as ciências da educação e outras afins. Assim sendo, enveredamos por este campo de estudos como forma de contribuir com a construção de saberes sobre o povo indígena, no nosso caso os Tembé, por fazerem parte do território da Amazônia paraense onde nós nos incluímos na função de professores e pesquisadores. 


\section{Procedimentos metodológicos}

\section{A seleção da amostra}

A seleção da amostra considerou os seguintes critérios: ser indígena, ser professor da educação escolar indígena, possuir formação em nível superior, residir nas aldeias. Com base nestes critérios apresentados, de um universo de 13 professores, selecionamos 4 professores indígenas como amostra para esse estudo.

Cumpre observar que os quatro professores indígenas que compõem a amostra são atuantes de forma permanente na educação escolar indígena, contudo não são servidores efetivos (atuam através de contratos).

As duas escolas Tembé, nas quais esses quatro professores se encontram distribuídos, receberam nomes fictícios, escola A e escola B, para assegurar o seu anonimato.

Destacamos que, embora os sujeitos tenham concedido autorização, através do Termo de Consentimento Livre Esclarecido (TCLE), seus nomes não serão divulgados. Assim, trataremos como professor Tembé ou professor indígena ou pela codificação alfanumérica: P1 e P2 os professores da escola A e P3 e P4 os professores da escola B.

\section{Os instrumentos da pesquisa}

instrumento adotado para a coleta das informações foi a entrevista narrativa (MUYLAERT; SARUBBI JR; GALLO; ROLIM NETO; REIS, 20 14), que consiste em estabelecer um diálogo entre entrevistador e entrevistado sobre um tema proposto e permite que o entrevistado fale sobre os aspectos mais relevantes da temática em investigação. Segundo estes autores, as informações, não surgem aleatoriamente, pois, apesar da liberdade de expressão dada ao entrevistado, o interlocutor/pesquisador incentiva o aprofundamento da temática pretendida.

roteiro prévio das entrevistas se dividiu em dois aspectos: a) a educação escolar e b) o futuro da aldeia. As entrevistas foram realizadas nos meses de setembro e dezembro de 2018 e primaram pela tranquilidade e descontração, importantes para a fluidez dos pensamentos dos entrevistados. 
que dizem os professores indígenas Tembé sobre a educação escolar e o futuro da aldeia: um estudo sobre as suas representações

\section{Os procedimentos de análise}

Optamos pela abordagem qualitativa de caráter explicativo e analítico, que possibilitasse o estudo de fenômenos complexos de natureza social e cultural com referência na Teoria das Representações Sociais de Moscovici para dar conta da nossa temática sobre as representações sociais de professores indígenas sobre a sua educação escolar e as implicações no futuro da aldeia.

Para a compreensão dos dados, segundo esta teoria, recorremos aos processos de objetivação e ancoragem que compõem as representações sociais de todo e qualquer grupo. Estes dois processos são fundantes na composição das representações sociais.

Na objetivação, segundo Moscovici (1978, p. 111) " [...] faz com que se torne real um esquema conceptual, com que se dê a uma imagem uma contrapartida material". Implica dizer que a objetivação de um objeto, acontecimento etc. é realizada pela construção da imagem mental sobre ele para the fornecer materialidade.

Enquanto que a ancoragem tem como função básica a integração do novo, a interpretação da realidade e a orientação dos comportamentos e das relações sociais (JODELET, 2001). Assim, a ancoragem é realizada pela construção de sentido sobre um objeto, acontecimento etc. para the fornecer existência na cadeia semântica de grupos sociais.

Para apreendermos as representações sociais dos professores Tembé sobre a educação escolar de seu povo, utilizamos como técnica a análise temática do conteúdo coletado nas entrevistas, de modo a destacar as objetivações e as ancoragens presentes em suas narrativas sobre a educação escolar. A partir destas representações, é possível sinalizar suas implicações para o futuro da aldeia Tembé.

Moscovici desnaturalizou a lógica individualista na produção de conhecimento sobre o sujeito para evidenciar e validar cientificamente o contexto psicossocial no qual os sujeitos se agrupam, interagem e produzem conhecimentos para abordar suas relações, acontecimentos e modos de vida em sociedade. Segundo o pesquisador romeno: 
[...] as representações sociais têm como finalidade primeira e fundamental tornar a comunicação, dentro de um grupo, relativamente não problemática e reduzir o 'vago' através de certo grau de consenso entre seus membros. [...] Elas são formadas através de influências recíprocas, através de negociações implícitas no curso das conversações, onde as pessoas se orientam para modelos simbólicos, imagens e valores compartilhados e específicos (MOSCOVICl, 2015, p. 208).

Desse modo, as representações sociais emergem a partir das trocas e negociações de conhecimentos partilhados e consensuados entre os sujeitos de um grupo social. Estes conhecimentos objetivam a construção da realidade e da vida simbólica de grupos sociais e, conforme Nascimento (20 14), mantém vínculos fundantes com a cultura concebida como um conjunto de atitudes, crenças e códigos de valores num determinado período histórico. Assim, essas construções orientam pensamentos, sentimentos e ações no dia a dia dos grupos.

Para Santos (2018, p. 86), a teoria das representações sociais "[...] traz a centralidade da 'simbologia social', percorrendo a 'ponte' que liga o microssocial ao macrossocial, ao âmbito do sujeito social sem 'esquartejá-lo' $[\ldots]^{\prime \prime}$, o que, em termos de análise, propõe compreender o sujeito dentro das relações de seu contexto sociocultural.

Na mesma direção, a principal pesquisadora e colaboradora de Moscovici, Denise Jodelet, compreende o sujeito como agente de um constructo social, o que o torna imprescindível à pesquisa em ciências humanas. Ela afirma que:

sujeito aparece sob diferentes figuras: a de uma ilusão ou de uma enganadora transparência; a de uma objetivação em subjetividades historicamente constituídas; a de um poder reflexivo de resistência ou de vigilância; a de uma liberdade que reivindica seus direitos, suas referências identitárias, sua responsabilidade; a de um desafio nos combates simbólicos e políticos (JODELET, 2009, p. 704).

Assim sendo, o sujeito emerge a partir da trama de relações nas quais esteja imerso e, nesse sentido, a relação aldeia-urbano, condicionante para a formulação de objetivações e ancoragens dos Tembé, constitui o desafio de "combates simbólicos e políticos", cujos sujeitos são parte integrante. 
O que dizem os professores indígenas Tembé sobre a educação escolar e o futuro da aldeia: um estudo sobre as suas representações

Concordamos com Nascimento (2004, p. 77) que afirma que "[...] a estrutura social, a comunicação e a cultura são as fontes de intercâmbio responsáveis pelas condições de produção e circulação das representações sociais".

Deste modo, para apreender as representações sociais dos professores indígenas consideramos a perspectiva psicossocial, utilizada por Serge Moscovici e aprofundada por Denise Jodelet, e a análise temática para o tratamento das narrativas dos professores. A análise permite realizar agrupamentos pelas unidades de sentidos, seguida da elaboração das respectivas temáticas de agrupamentos e, assim, possibilitar a "visão consensual da realidade" (JODELET, 2001) dos professores entrevistados sobre a educação escolar.

Em síntese, realizamos os seguintes procedimentos no tratamento dos dados: 1) digitação e organização individual das entrevistas de acordo com cada sujeito; 2) agrupamento dos dados em unidades de sentidos seguido da elaboração de temáticas correspondentes a cada agrupamento.

\section{As representações sociais de professores Tembé}

Após o segundo momento do tratamento dos dados, identificamos as três temáticas: educação escolar, futuro da aldeia e desafios que representam os eixos centrais, vistos como uma trigrama de onde emanam as imagens e o sentidos que respectivamente se inscrevem nas objetivações e ancoragens sobre a educação escolar e o futuro da aldeia.

\section{A educação escolar}

A educação comparece nas narrativas desses professores Tembé vinculada ao sentido de escola e ensino-aprendizagem, como ato políitico capaz de prover melhorias e mudanças na vida da aldeia, capaz de proporcionar compreensão crítica do mundo e problematizar suas dúvidas, incertezas e ameaças.

Dessa maneira, a educação escolar segundo estes professores deve estar em consonância com a cultura dos Tembé para que a identidade e a língua do povo sejam garantidas, uma vez que a educação escolar é o caminho para a consciência crítica e reflexiva sobre o território e a relação 
identitária que mantém. Além disso, a educação contribui com a compreensão das modificações ocorridas ao longo do tempo na relação indígena-branco, indígenas-indígenas e sujeito-meio ambiente.

Quaresma e Ferreira nos ajudam a compreender a visão de educação que os professores possuem e desejam para seu povo:

Os indígenas olham o mundo e os fatos da vida de um modo particular, por isso sua filosofia de educação sobre os processos e as condições de transmissão da cultura, sobre a natureza dos saberes ensinados e sobre as funções sociais da educação se constituía de modo muito diferente da filosofia educacional adotada pelos não-índios (QUARESMA; FERREIRA, 2013, p. 232).

Nessa direção, para quatro sujeitos pesquisados, a educação aparece como um elemento fundamental na estruturação e organização dos mais diversos aspectos da vida na aldeia (materiais e imateriais) e na relação com o espaço e culturas urbanos, uma vez que, para os professores, a educação é ensino, aprendizagem, conhecimento e luta.

Freire (1987, p. 30) reflete que a educação enquanto ato político deve superar a coisificação do sujeito de maneira que se torne plenamente consciente de sua autonomia, humanizado, porque a humanização é uma vocação dos homens, mas é "[...] negada na injustiça, na exploração, na opressão, na violência dos opressores". Como na fala do professor Tembé:

O papel do professor indígena é fazer as crianças compreender nossa história e fazer elas valorizar... não é pra mandar o índio pra fora da aldeia... é pra ele servir pra comunidade... ele tem que ser consciente. [...] antes, nós não sabia dos nossos direitos. Agora, a gente já consegue lutar por eles na conversa e, isso foi dado pela educação (PROFESSOR P4, 2018).

A fala do professor deixa clara a importância da escolarização para o povo Tembé e a necessidade de consciência identitária, pois, a escola é, ao mesmo tempo, a valorização da identidade e a inserção de estruturas homogeneizadoras, as quais produzem representações que "[...] são impostas sobre nós, transmitidas e são produto de uma sequência completa de elaborações e mudanças que ocorrem no decurso do tempo e são resultado de sucessivas gerações" (MOSCOVICl, 2015, p. 37). 
que dizem os professores indígenas Tembé sobre a educação escolar e o futuro da aldeia: um estudo sobre as suas representações

Representações consolidadas na sociedade urbana tendem a se transplantar para a aldeia. Em atenção a isso, o RCNEl enumera que a relação entre conhecimentos tradicionais e conhecimentos da contemporaneidade atua de maneira conflituosa na escola enquanto instituição cujos objetivos são voltados ao futuro.

[...] tensão entre conhecimentos indígenas e ocidentais, entre políticas públicas e política de aldeias, entre tendências políticas internacionais e a definição de estratégias e de opções específicas de vida e de futuro para populações indígenas. Supõe-se que estas tensões, de cunho eminentemente político, passem pela escola indígena, fazendo dela palco para o diálogo ou o conflito entre essas forças em interação (BRASIL, 1998).

Embora as normas, dispostas na Lei de Diretrizes e Bases da Educação Nacional (LDB n 9.394/96) e no Referencial Curricular Nacional para as Escolas Indígenas (RCNEI) primem pela valorização, o entendimento e o respeito entre seres humanos de identidades diferentes e reconheça a necessidade de conservação da diversidade cultural e linguística, é no currículo que 12 as perspectivas culturais diversas são colocadas de maneira hierarquizada, geralmente, sob o prisma da superioridade dos conhecimentos acadêmicos em detrimento dos conhecimentos tradicionais.

A função da educação indígena é fazer com que os alunos indígenas tenham um aprendizado sobre a cultura do branco e sobre a cultura do índio [...]. Tem que valorizar o nosso conhecimento. [...] Nós precisamos crescer principalmente com o conhecimento (PROFFESSOR P1, 2018).

É comum "[...] escolher um dos paradigmas estocados na memória e estabelecer uma relação positiva ou negativa com ele [...]" (MOSCOVICl, 2015, p. 63) daí a representação sobre o indígena e seus saberes tradicionais estar carregada de imagens confeccionadas no passado, que os concebem ou como ingênuos, ou como ameaçadores. $\bigcirc$ que contrasta com os indígenas da atualidade: sujeitos de direitos tanto de "[...] perpetuação de suas tradições, valores e costumes, quanto do acesso aos bens que norteiam o mundo como um todo" (PEREIRA FILHO; PINTO, 2017. p. 138). 
Acreditamos que um currículo organizado de acordo com as necessidades das comunidades indígenas, com a incorporação e o respeito aos conhecimentos tradicionais, é capaz de propiciar o desenvolvimento dessas comunidades sem impor a homogeneização. Por isso, concordamos com Walsh (2009) sobre a necessidade de formação e escolarização dos sujeitos numa perspectiva intercultural para que estabeleçam, eles próprios, a formação das gerações futuras. A interculturalidade é, neste sentido, o reconhecimento do direito à identidade.

A função da educação indígena é ensinar o índio as coisas do branco. [...] Tem gente que acha que tem que ensinar o índio a ser índio. Índio nós já somos! Tem que ter um pouco de cada coisa, por que tem que valorizar quem nós somos... (PROFESSOR P2, 2018).

Para os professores Tembé, a necessidade de compreensão do outro, da cultura do branco, por meio dos processos de escolarização, não constitui uma busca por inserção em mercados de trabalho - embora seja um direito que possuem enquanto cidadãos - ou uma disputa por posições privilegiadas na sociedade contemporânea, mas sim uma forma de prover condições para luta e defesa de direitos já adquiridos. Essa é a imagem e o sentido atribuído pelo indígena à educação e à escola.

Agora, essa relação com a outra sociedade [capitalista], nós não temos como frear. Não temos mais como evitar e não é bom evitar porque a gente precisa também crescer, principalmente com conhecimento, com o objetivo de se preparar pra discutir os nossos direitos futuros... não é com objetivo de buscar mercado, disputar mercado (PROFFESSOR P2, 2018, grifos nossos).

Na atualidade, é inevitável a relação entre as diversas culturas. A interculturalidade corresponde à tentativa de não sobrepor uma cultura à outra. Assim, é fundamental pensar a relação entre aldeia e urbano como um cenário no qual os protagonismos nas relações de produção do espaço existem baseados na educação e no conhecimento.

[...] tudo isso passa pela educação... e a nossa preocupação é que a gente imagina que se não fortalecer essa luta, daqui a 20 anos, a Amazônia tá completamente invadida por pessoas que não pensa no futuro, nas novas gerações. Não pensa! Vai matar, 
O que dizem os professores indígenas Tembé sobre a educação escolar e o futuro da aldeia: um estudo sobre as suas representações

destruir, indígenas, quilombolas, ribeirinhos... [.. ] ao redor das terras indígenas tudo já foram destruídas... e a visão dos grandes latifundiários agora são as terras indígenas... se não tiver muita força, muita fiscalização, muita compreensão... a gente vai perder e, perdendo as nossas terras é o mesmo que dizer matou o indígena, acabou o indígena! (PROFESSOR P3, 2018).

Desde a Constituição Federal de 1988, os indígenas vêm conquistando espaço nos diversos âmbitos sociais, especialmente através da escolarização, ainda que as ações sejam discutíveis. Entretanto, garantias como a educação escolar de qualidade, bilíngue e intercultural figuram como um ônus que estados geralmente se recusam a assumir.

Muitas escolas indígenas possuem propostas de ensino que caracterizamos como escolas para a educação dos indígenas nos moldes da sociedade urbano-industrial e não verdadeiramente escola de educação indígena, onde se valorize a relação da identidade e os conhecimentos tradicionais.

\section{O futuro da aldeia}

A palavra futuro surge nas narrativas dos quatro professores relacionada a um tempo muito próximo do agora, povoado por incertezas e as ameaças. François Hartog (2014) chama isso de presentismo, quando o tempo presente é ampliado por causa das questões e soluções dos problemas atuais. Com efeito, esses professores não se permitem vislumbrar ou sequer planejar um futuro, na medida em que as ameaças predominam no tempo presente.

Esse futuro é vivido nos dias de hoje com o sentimento de insegurança pela ameaça de perda de seus territórios. A dimensão territorial é representada pelos professores como indissociável da dimensão sociocultural e educacional (OLIVEIRA; HAGE, 201 1). Assim, é consenso para os professores que a relação dos povos indígenas com seus territórios é condição preponderante para a manutenção da biodiversidade, do ecossistema amazônico, bem como a preservação da riqueza étnica e cultural.

A conjuntura política atual é a da retirada de direitos dos povos indígenas. As ameaças contra a vida desses povos fazem parte da contemporaneidade brasileira. As determinações contra os territórios, culturas e riquezas 
indígenas são cada vez mais presentes ao nos depararmos com a política neoliberal, implantada pelo governo de nosso país.

Ao analisarmos as perspectivas de futuro para os povos indígenas sob o prisma da interlocução entre a aldeia e o urbano, observamos que 3 professores Tembé compreendem os aspectos relativos à língua e aos problemas de ordem socioeconômica, educacional e ideológica, como correspondentes de sua trajetória de resistência. Um deles compreende o futuro independentemente da trajetória pregressa. Entretanto é consenso entre os professores a necessidade de pensar mais profundamente os projetos de futuro diante da atual conjuntura sócio-política do país, observando com ressalvas quaisquer perspectivas para o futuro. Assim observamos na narrativa do professor indígena.

Meu pai me dizia: Olha meu filho, antigamente a gente só falava a língua indígena. A gente não sabia falar português... A gente não usava a faca, a agente não usava o terçado, não usava o machado, a gente piraquerava [...] hoje, aqui na aldeia, nós já temos casas diferentes e outras coisas (PROFFESSOR P 1, 2018).

A partir das reflexões do professor Tembé sobre passado, presente e futuro, percebemos que a manutenção da identidade de seu povo se apresenta como um elemento fundamental para a resistência e existência da aldeia, uma vez que os vetores de modernização atingem as comunidades indígenas de forma a eliminar determinados ritos e costumes, através da substituição de elementos da organização das estruturas tradicionais, como os citados por nosso interlocutor.

Não é possível compreender a aldeia em sua relação com o urbano sem compreender a herança de períodos anteriores nos quais suas histórias eram contadas através das lentes do colonizador. A história protagonizada e vista pelo próprio indígena, e sobre si mesmo, dependia quase exclusivamente dos sistemas de contação de histórias. Estes sistemas, em muitos casos, se perderam no espaço e no tempo, naturalmente ou pela ação homogeneizadora do estado. Enquanto herança de tais períodos, a atualidade está repleta de mecanismos que pretendem "[...] anular as cosmovisões, filosofias, religiosidades, princípios e sistemas de vida, ou seja, a continuidade civilizatória das comunidades indígenas" (WALSH, 2009, p. 15).

Essa anulação é potencializada nas comunidades indígenas pela perda de seus anciões, como expressa o professor indígena: 
O que dizem os professores indígenas Tembé sobre a educação escolar e o futuro da aldeia: um estudo sobre as suas representações

Nós temos hoje 78 pessoas idosas com mais de 50 anos [...] só isso aqui no Guamá [TIARG] então nossa comunidade é muito jovem. Então eles [idosos] conversam [...] porque quem domina o Brasil é a sociedade capitalista e os capitalistas pensam somente em derrubar a floresta... (PROFESSOR P3, 2018, grifos nossos).

número de idosos na aldeia, portanto, também constitui um grande desafio, posto que a educação dos jovens Tembé deveria passar, invariavelmente, por uma cadeia de transmissão geracional, onde os mais jovens aprendessem com os mais velhos, desde aspectos simples da vida cotidiana em comunidade a aspectos mais complexos como hierarquia e políticas de aldeia. Porém, tal cadeia de transmissão também encontra novos desafios como o progressivo desinteresse dos mais jovens e até de alguns idosos.

Tais desafios se apresentam internamente, mas, externamente, as forças capitalistas trabalham continuamente para mitigar direitos e garantias conquistados por gerações anteriores, como explicita a fala do professor: "[...] eles querem fazer revisão dos nossos direitos na Constituição Federal [...] querem mexer nos artigos dos índios" (PROFFESSOR P1, 2018).

\section{Os desafios}

Ao efetuar a análise das entrevistas, constatamos que, unanimemente, os entrevistados se reportam a um futuro incerto sobre os seus territórios, sobre a escola e sobre os processos de resistência que garantem a sobrevivência de suas identidades. Nesta perspectiva, os desafios, a dúvida e a insegurança são imagens presentes nas representações sociais que os professores Tembé possuem sobre a escola e que implicam no futuro de sua aldeia. Tais imagens se ancoram fortemente em sentidos e incertezas, dúvidas sobre a educação escolar e o futuro do povo Tembé. Essas representações sociais se projetam e se materializam em muitos aspectos da vida dos Tembé, orientando suas ações para o que acreditam ser a única alternativa para seu povo, sintetizada na fala do professor: "[...] vai ser preciso muita luta!" (PROFESSOR P3, 2018).

Os Tembé, assim como outras etnias, vivem numa contraditória condição no que diz respeito ao acesso à escola e a recursos e inovações tecnológicas, bem como a políticas públicas e políticas de estado, pois, estes elementos se projetam sobre a aldeia, ao mesmo tempo, como avanços e 
desafios para a cultura e identidade desse povo, uma vez que produzem muitas incertezas. Tal condição está presente na narrativa do professor Tembé, confirmando a necessidade de luta contínua: " $E$, a gente conversa sobre isso... daqui a 10 anos como nós estamos? [...] os mais velhos dizem: [...] nós temos que se preparar, porque muita coisa vai mudar, mas nós não pode (sic) deixar de ser o que nós somos" (PROFFESSOR P1, 2018).

Por tudo, é importante notar que a luta do povo Tembé é travada sobretudo para garantir sua cultura, suas terras, seus territórios e sua identidade. $\bigcirc$ que justifica as representações sociais desse povo estarem organizadas a partir de dúvidas e incertezas, no momento em que se configuram posições político-ideológicas radicais, que ameaçam o futuro da aldeia e das populações indígenas em geral, principalmente, quando estas posições se expressam a partir de concepções etnocêntricas, propagadas institucionalmente pelo governo brasileiro, que se inclina contra os povos originários da Amazônia.

\section{Conclusões}

$\bigcirc$ estudo das representações sociais de professores indígenas sobre a educação e o futuro da aldeia revela que as objetivações e ancoragens que constituem as suas representações se articulam ao consenso de que a educação indígena deve promover o fortalecimento da identidade, da cultura e das relações do povo Tembé com o seu território de origem.

Quanto ao futuro, a construção e a realização dos projetos dos Tembé assinalam a suspensão em suas ações, na medida em que o momento político pelo qual o nosso país passa faz com que as incertezas sejam maiores para a população. $\bigcirc$ sistema político-econômico imposto pelo atual governo no Brasil é, sem dúvidas, contrário aos nativos da Amazônia brasileira. Desse modo, o desejo de um Brasil sem territórios indígenas demarcados alimenta uma política que desterritorializa esses povos de suas terras e, consequentemente, dos seus direitos e das políticas de saúde, juntamente com o sucateamento da Fundação Nacional do Índio (FUNAI).

As riquezas do subsolo das terras indígenas constituem-se em forte atrativo para que os nossos governantes priorizem os lucros de interesse empresarial privado, ao invés da manutenção do vínculo entre o povo indígena 
O que dizem os professores indígenas Tembé sobre a educação escolar e o futuro da aldeia: um estudo sobre as suas representações

e a biodiversidade amazônica, fundamental para a vida não somente na Amazônia, mas de todo o planeta.

Desse modo, a educação, o futuro e os desafios compõem as representações sociais dos professores Tembé. A educação, como direito, e ainda como entidade capaz de dar sustentação aos direitos destes povos indígenas, não pode se constituir em mais um elemento de mitigação da cultura e dos seus saberes. Vale, portanto, pensar em programas interculturais que não representem ameaças nem desconstruam os modos de vida e suas relações com o ecossistema dos povos indígenas.

Nesse sentido, as falas dos professores apontam para o desejo por uma educação que atenda às demandas do povo indígena Tembé e à realização de projetos para o futuro direcionam ações de resistência e luta para a superação dos desafios que nos parecem um aspecto de destaque em suas representações sociais e ações no momento atual.

\section{Notas}

1 Para os Tembé, todo e qualquer indivíduo não-indígena é chamado de Branco.

182 Piraquera, para os Tembé, é a pesca noturna onde se usa arpão artesanal para capturar o peixe.

\section{Referências}

BRASIL. Lei $\mathbf{n}^{\circ}$ 6.001, de 19 de dezembro de 1973. Dispõe sobre o Estatuto do Índio. Disponível em: http://www. planalto.gov.br/ccivil_03/LEIS/L6001.htm. Acesso em: 27 de jul. 2018.

BRASIL. Lei $\mathbf{n}^{\circ} \mathbf{9 3 9 4}$, de 20 de dezembro de 1996. Estabelece as diretrizes e bases da educação nacional. Disponível em: http://www.planalto.gov.br/ccivil_03/Leis/L9393. htm. Acesso em: 30 out. 2017.

BRASIL. RCNEI - Referencial Curricular Nacional para as Escolas Indígenas. Brasília: MEC/SEF, 1998.

BRASIL. Plano de gestão territorial e ambiental da Terra Indígena do Alto Rio Guamá: povo Tembé Tenetehar da terra indígena Alto Rio Guamá. Brasília: ECAM, 2018.

$\mathrm{COHN}$, Clarice. Educação escolar indígena: para uma discussão de cultura, criança e cidadania ativa. Revista Perspectiva, Florianópolis, v. 23, n. 2, p. 485-515, jul./dez. 
2005. Disponível em: https://periodicos.ufsc.br/index.php/perspectiva/article/download/9804/9038. Acesso em: 30 ago. 2018.

ALMEIDA, Angela Maria de Oliveira. A pesquisa em representações sociais: propostas teórico-metodológicas. In: SANTOS, Maria de Fátima de Souza; ALMEIDA, Leda Maria de. (Orgs.). Diálogos com a teoria das representações sociais. Alagoas: Editora UFPE, 2005.

FREIRE, Paulo. Pedagogia do oprimido. Rio de Janeiro: Paz e Terra, 1987.

GUARANY, Vilmar Martins Moura. Desafios e perspectivas para a construção e o exercício da cidadania indígena. In: ARAÚJO, Ana Valéria. Povos Indígenas e a Lei dos "Brancos": o direito à diferença. Brasília: MEC/UNESCO, 2006.

HALL, Stuart. A identidade cultural na pós-modernidade. Rio de Janeiro: DP\&A, 2006.

HARTOG, François. Regimes de historicidade: presentismo e experiências do tempo. Tradução Andréa Souza de Menezes, Bruna Breffart, Camila Rocha de Moraes, Maria Cristina de Alencar Silva e Maria Helena Martins. Belo Horizonte: Autêntica, 2014.

IBGE. Instituto Brasileiro de Geografia e estatística. Censo Demográfico 2010. 2010. Disponível em: https://censo2010.ibge.gov.br/resultados.html. Acesso em: 10 mar. 2017.

JODELET, Denise. $\bigcirc$ movimento de retorno ao sujeito e a abordagem das representações sociais. Sociedade e Estado, Brasília, v. 24, n. 3, p. 679-712, set./dez. 2009. Disponível em: http://www.scielo.br/pdf/se/v24n3/04.pdf. Acesso em: 25 mar. 2018.

JODELET, Denise. Representações sociais: um domínio em expansão. In: JODELET, Denise (Org.). As representações sociais. Rio de Janeiro: EdUERJ, 2001.

MARRA, Maria Lúcia Martins Pedrosa. "Escola itinerante": uma experiência de formação de professores indígenas no estado do Pará, Brasil. 2015, 291 f. Tese (Doutorado em Educação) - Programa de Pós-Graduação em Educação, Universidade Federal do Pará, 2015.

MAROLDI, Alexandre Masson. A produção científica sobre educação indígena no Brasil: uma revisão narrativa. RIAEE - Revista Ibero-Americana de Estudos em Educação, Araraquara, v. 13, n. 3, p. 931-952, jul./set. 2018 . Disponível em: https://periodicos.fclar.unesp.br/ iberoamericana/article/viewFile/10211/7458. Acesso em: 24 mar. 2019.

MIRANDA, Júlia Cleide Teixeira de. $\bigcirc$ ritual da festa do moqueado na sociedade indígena Tembé-Tenetehara: teias e tramas de saberes. In: CONGRESSO NACIONAL DE EDUCAÇÃO - EDUCERE. 12, 2015. Curitiba. Anais [...]. Curitiba: Pontifícia Universidade Católica do Paraná. Disponível em: http://educere.bruc.com.br/arquivo/pdf2015/19426_11546. pdf. Acesso em: 2 abr. 2018. 
O que dizem os professores indígenas Tembé sobre a educação escolar e o futuro da aldeia: um estudo sobre as suas representações

MOSCOVICl, Serge. Representações sociais: investigações em psicologia social. Rio de Janeiro: Vozes, 2015.

MOSCOVICl, Serge. A representação social da psicanálise. Rio de Janeiro: Zahar Editores, 1978.

MUYLAERT, Camila Junqueira; SARUBBI JR., Vicente; GALLO, Paulo Rogério; ROLIM NETO, Modesto Leite; REIS, Alberto Olavo Advincula. Entrevistas narrativas: um importante recurso em pesquisa qualitativa. Revista da Escola de Enfermagem da USP, São Paulo, n. 48, n. 2, p. 193-199. 2014. Disponível em: http://www.scielo.br/pdf/reeusp/v48nspe2/ pt_0080-6234-reeusp-48-nspe2-00184.pdf. Acesso em: 10 ago. 2018.

QUARESMA, Francinete de Jesus Pantoja; FERREIRA, Marília de Nazaré de Oliveira. Os povos indígenas e a educação. Revista Práticas de Linguagem, Universidade Federal de Juiz de Fora, n. 2, v. 3, jul./dez. 2013. Disponível em: http://www.ufjf.br/praticasdelinguagem/edicoes-2/edicoes/volume-3-n-2/. Acesso em: 24 set. 2019.

NASCIMENTO, Ivany Pinto. A identidade da teoria das representações sociais. Revista Ver a Educação, Belém, v. 10, n. 1 e 2, jan./dez. 2004.

NASCIMENTO, Ivany Pinto. Educação e projeto de vida de adolescentes do ensino médio.

20 EccoS-Revista Científica, São Paulo, n. 31, p. 83-100, maio/ago. 2013. Disponível em: http://www.redalyc.org/pdf/715/71529334006.pdf. Acesso em: 4 abr. 2019.

NASCIMENTO, Ivany Pinto. $\bigcirc$ campo das representações sociais: articulações possíveis. Agália - Revista de Estudos na Cultura, Santiago de Compostela, n. 107. p. 181-203, 2014.

OlIVEIRA, Lorena Maria Mourão de; HAGE, Salomão Antonio Mufarrej. A socioterritorialidade da Amazônia e as políticas de educação do campo. Revista Ver a Educação, Belém, v. 12, n. 1, p. 141-158, jan./jun. 2011.

PEREIRA FILHO, Gerson; PINTO, Alírio Ferreira. "De selvagem a cidadão": representações sociais do índio no ensino fundamental. Sapereaude, Belo Horizonte, v. 8, n. 15, p. 128-145, jan./jun. 2017. Disponível em: http://periodicos.pucminas.br/index.php/ SapereAude/article/download/P.2 177-6342.2017v8n 15p128/12030. Acesso em: 30 mar. 2019.

PROFFESSOR P1. Entrevista. Aldeia São Pedro (Pará), 14 set. 2018.

PROFFESSOR P2. Entrevista. Aldeia São Pedro (Pará), 14 set. 2018.

PROFFESSOR P3. Entrevista. Aldeia Itwaçu (Pará), 7 dez. 2018. 
PROFFESSOR P4. Entrevista. Aldeia Itwaçu (Pará), 7 dez. 2018.

SANTOS, Antônio Luís Parlandin dos. Representações sociais de professores do ensino fundamental sobre educação étnico-racial e as implicações em sua prática pedagógica: por uma pedagogia descolonial e intercultural. 2018, 282f. Tese (Doutorado em Educação) - Programa de Pós-Graduação em Educação, Universidade Federal do Pará, 2018.

TEIXEIRA-PINTO, Márnio. leipari: sacrifício e vida social entre os índios Arara. Rio de Janeiro: Hucitec, 1997.

WALSH, Catherine. Interculturalidade crítica e pedagogia decolonial: in-surgir, re-existir e re-viver. In: CANDAU, Vera Maria Ferrão (Org.). Educação intercultural na América Latina: entre concepções, tensões e propostas. Rio de Janeiro: 7 Letras, 2009.

Prof. 'Titular Dra. Ivany Pinto Nascimento Universidade Federal do Pará (Brasil) (Campus Guamá - Belém) Instituto de Ciências da Educação Programa de Pós-Graduação em Educação Bolsista produtividade CNPq Líder do Grupo de Estudos e Pesquisa sobre Juventude, Representações Sociais e Educação (GEPJURSE/CNPq) ORCID ID: https: / / orcid.org/0000-0002-2455-3676 E-mail: ivany.pinto@gmail.com

Ms. Glauber Ranieri Martins da Silva Doutorando do Programa de Pós-Graduação em Educação Universidade Federal do Pará (Brasil) 
Artigo

O que dizem os professores indígenas Tembé sobre a educação escolar e o futuro da aldeia: um estudo sobre as suas representações

(Campus Guamá - Belém)

Grupo de Estudos e Pesquisas sobre Juventude, Representações Sociais e Educação

(GEPJURSE/CNPq)

Grupo de Estudo e Pesquisa em Educação do Campo na Amazônia (GEPERUAZ/

$\mathrm{CNPq}$

ORCID ID: https: / / orcid.org/0000-0003-4859-8542

E-mail: glauberranieri@yahoo.com.br

Recebido 16 maio 2019

Aceito 20 set. 2019 